\title{
Consumerism and general practice
}

\author{
Ralph Leavey, David Wilkin, David H H Metcalfe
}

This article and the following interview with Dr W J Appleyard are the fifth and sixth in a series on the white paper Working for Patients and its accompanying working papers. The series started on 18 February (p 437).
Centre for Primary Care Research, Department of General Practice,

University of Manchester Manchester M14 5NP

Ralph Leavey, MPHIL, research fellow

David Wilkin, PHD, associate director

David H H Metcalfe, FRCGP, professor

Correspondence to: $\mathrm{Mr} \mathrm{R}$ Leavey, Centre for Primary Care Research, Department of General Practice,

University of Manchester, Rusholme Health Centre, Walmer Street, Manchester M14 5NP.
In the current political and economic climate market forces reign supreme when it comes to regulating the quantity and quality of goods and services. The NHS is no exception to the government's determination to foster competition and enhance the power of the consumer. The white paper Working for Patients recommends ways of using the power of the market to improve health services.'

The review aims to attach a clearer monetary value to patients by making capitation a much larger element of general practitioner remuneration and through the proposed budget scheme for large practices. Practices and hospitals "which attract the most custom will receive the most money." Thus, "both general practitioners and hospitals will have a real incentive to put patients first." In the interests of providing a better service "general practitioners will be encouraged to compete for patients." To achieve this "it will be easier for patients to choose (and change) their own general practitioner as they wish." The strategy rests on

\section{... the proposals advanced by ministers owe more to political ideology and rhetoric.}

patients making decisions about their doctor in comparison with others.

Before embracing the new consumerism in health care with unqualified enthusiasm it is advisable to examine the premises on which its success will depend. It relies on patients (consumers) being willing and able to exercise choices about their doctors in the same way as they do about restaurants, hairdressers, or supermarkets. In order for the market mechanism to work consumers need to possess the motivation to exercise choice, a range of alternatives from which to choose, information about those alternatives, the competence to make a rational choice, and the opportunity to implement their choice once it has been made. Although the white paper repeatedly asserts the importance which ministers attach to greater consumer choice, it contains no analysis of the extent to which these conditions are currently met.

\section{Motivation to exercise choice}

Most people change their doctor only when circumstances force them to do so, either because they have moved or because their general practitioner has retired, moved, or died. Only 5\% change doctors because they are dissatisfied with the treatment or attitude of their existing doctor. ${ }^{2}$ Perhaps more importantly from the point of view of motivation is the finding that only one in ten people even think about changing their doctor. ${ }^{2-4}$ The vast majority are, rightly or wrongly, satisfied with their present doctor.

The reasons for this lack of motivation to consider alternatives are not hard to find. The nature of people's need for the services of general practitioners and the circumstances in which it arises do little to motivate them to embark on a search for a better doctor. For many their need for medical care is spasmodic and minimal. If contact with the doctor is limited to 10 minutes a year for a prescription for a cough or cold why spend much time thinking about alternatives? When an urgent need does arise because of a serious illness the very fact that it requires urgent treatment precludes the possibility of shopping around. For patients suffering from chronic conditions the reasons for inertia are different but no less powerful. The doctor has become an important part of their lives. The relationship of trust and confidence which has been established during the course of the illness provides a powerful motivation to stay put.

Nevertheless, some patients are dissatisfied and it is possible that more would consider a change if they were aware of alternatives. The College of Health has suggested that there are patients who wish to change their doctors but who believe that to make such a move is difficult and that it would mark them as someone who is "a problem."

\section{Range of accessible alternatives}

The notion of consumer choice can be meaningful only if there is a range of alternatives from which to choose. Although there are 30000 general practitioners in the United Kingdom, various factors combine to limit the choice available to most people to perhaps three or four practices, and for many of those living in rural areas to only one practice. The simple geographical distribution of doctors places important constraints on the potential effects of any attempt to create a more competitive environment. ${ }^{6}$

On top of the basic geographical constraints are a series of additional factors that further restrict the range of choices practically available. Constraints imposed by general practitioners include the drawing of practice boundaries, unwillingness to accept patients leaving another practice, ceilings on list size, and deliberate exclusion of certain categories of patient - for example, those living in temporary accommodation. The increased emphasis on the capitation component in general practitioners' remuneration may help to remove some of these constraints in some areas, but if some practices are made uneconomic as a consequence the range of alternatives on offer will be reduced. Constraints which differentially affect particular groups of consumers include the availability of transport, financial resources, time, work commitments, family commitments, etc. As a consequence some people have potential access to a much greater range of alternatives than others.

It is not clear whether the proponents of the market model wish to encourage diversity or uniformity. On the one hand, they tend to talk about the need to provide consumers with a range of choices; on the other hand, they wish to promote uniformly high standards of care. The market mechanism tends to be good at producing diversity-as, for example, in the range of restaurants available-but perhaps less good at producing uniform standards of excellence. British 
general practice is already characterised by extreme diversity in every aspect of provision and patterns of care. Do we expect greater consumer sovereignty to encourage this diversity or reduce it?

\section{Information}

If consumers have the motivation to exercise choice and a range of alternatives from which to choose, they then require adequate information about those alternatives. The white paper says that practices will be encouraged to produce and distribute information about the services they offer. But research shows a low level of demand for information from consumers when choosing a new doctor. Ritchie reported that $70 \%$ of patients did not want to know anything about the organisation or the size of the prospective practice. Only one in 10 wanted to know whether there was an appointments system, what surgery times were, how available doctors were, or whether the practice ran special clinics. ${ }^{2}$

Many practices already provide basic information about such aspects of their work as surgery hours and arrangements, but few say much about the doctors, except perhaps their names and their qualifications (usually without explanation). Many would be reluctant to provide more information, and there would be problems in deciding what information was relevant and useful. Should practices, for example, provide information about their prescribing habits or referral rates? If such information were available how much use would it be to patients faced with a choice between practice $A$ and practice $B$ ?

For those consumers who want information the problem is one of where to obtain it. While individual practices may issue leaflets, the only central compilation of information is the family practitioner committee list of general practitioners. But a survey carried out in London reported that only one in five of those who had registered with a general practitioner in the past five years had even heard of the family practitioner committee. The information provided by family practitioner committees is variable but generally limited and its distribution is haphazard. For example, only one in six family practitioner committees provide information about daytime reception cover. ${ }^{8}$ The prospect of more sophisticated information being routinely available to patients seems fairly remote.

\section{Competence to make a choice}

The market mechanism is only an effective means of improving standards if consumers are capable of making rational decisions, having weighed the benefits and costs of the available alternatives. A fundamental problem inherent in the view of the patient as a consumer is that the service provided is only an imperfect means to the desired end. The commodity sought by patients is health, not medical care per se. While patients may be the best judges of this desired commodity they may not possess the necessary competence to judge the quality of care provided. Despite the fact that this argument has rightly aroused suspicion when it has been used by doctors as a means of sustaining professional power, it remains a strong argument. If the judgment of a doctor's technical competence to distinguish between a minor self limiting complaint and a serious life threatening illness relies only on the patient's assessment of final outcome the consumer may find that it is too late to exercise choice.

There are, of course, many aspects of general practice about which consumers are perfectly competent to make a choice, including characteristics of the doctor, surgery hours, availability of clinics, appoint- ment systems, surgery facilities, other services, etc. It would, however, be unfortunate if these were to be elevated above clinical competence in the desire to enhance consumer sovereignty.

If all other conditions are met and the consumer is able to make a choice there remains the need to provide an opportunity to implement that choice. The proposal to allow patients to change their doctors without approaching their existing general practitioners or the family practitioner committee is a welcome step towards enabling them to implement choices. Nevertheless, even with the removal of restrictive procedures, the registration system will remain a constraint.

\section{... the market mechanism is effective only if consumers are capable of making rational decisions.}

Changing doctors will still require patients to go through a formal procedure. Unlike consumers of other goods and services consumers of health care are unable to sample alternatives or to use a different supplier as and when they think it is appropriate. Without abandoning the undoubted advantages of the registered population, and thus transforming the organisation of health care under the NHS (with a consequent increase in cost), registration requirements will remain an obstacle to consumers' freedom to exercise choice.

\section{Scope for consumerism in general practice}

The proposals advanced by ministers owe more to political ideology and rhetoric than they do to an analysis of how people actually set about choosing a doctor. The little evidence we have suggests that few people behave in the way implied by the classic market model. Surveys show that convenience and tradition rather than an evaluation of available alternatives largely determine the choice of general practitioner. Most people inherit their doctor or simply choose the nearest practice. Only a minority take into account a recommendation, and this is usually from friends, relatives, or neighbours. ${ }^{2+}$ Once registered there is little incentive to change. Ritchie reported that four out of five adults had been with their present practice for five years or more, and during a year only $4 \%$ had registered with a new doctor. ${ }^{2}$ Most people change doctors only when circumstances force them to do so rather than for positive reasons, such as the possibility of obtaining a better standard of service elsewhere.

The issue of choice might be expected to be more relevant in the American system, where market forces can play a much greater role. Kronenfeld reported that nearly $60 \%$ of the people in her United States sample named two or more doctors practising in different locations as their "regular" doctors. ${ }^{9}$ This implies that American patients have far greater opportunity to shop around and compare the alternatives on offer. A recent study, however, found that fewer than $40 \%$ of people surveyed engaged in consumerist behaviours, which were defined as willingness to seek out information, readiness to exercise independent judgment, and readiness to make quality comparisons when selecting a doctor. ${ }^{10}$ This suggests that any move to increase consumer choice in Britain, starting from a much lower threshold, is likely to face considerable inertia. Whatever its applicability in other areas of the provision of services, we believe that the market mechanism is 
unlikely to yield any dramatic improvements in the quality or efficiency of general practitioner care. This is not to suggest that we disagree with the government's objective of making general practitioner services more responsive to the needs and wishes of consumers or of raising standards of practice.

We believe that these objectives will not be realised by simple reliance on individual consumer choice, at least within the confines of the present system. There are other ways in which the collective wishes of consumers of health care can be expressed and in which the quality of care can be improved. In this context we welcome proposals to increase the role of medical audit in ensuring high quality care.

It is unfortunate but perhaps not surprising that the white paper contains no proposals to enhance the power of consumers collectively to influence the service through community health councils or increased representation on family practitioner committees. There are no solutions which will solve all problems at a stroke, and it would be naive of ministers to assume that the application of market principles will achieve major improvements in primary health care.

1 Secretaries of State for Health, Wales, Northern Ireland and Scotland. Working for Patients. London: HMSO, 1989. (Cmnd 555.)

2 Ritchie J, Jacoby A, Bone M. Access to primary health care. London: HMSO 1981.

3 Simpson R. Access to primary care. Royal Commission on the NHS/National Consumer Council research paper No. 6. London: HMSO, 1979.

4 Cartwright A, Anderson R. General practice revisited: a second study of patients and their doctors. London: Tavistock, 1981.

5 College of Health. Comments on primary health care discussion paper. London: Crllege of Health, 1987

6 Butler JR, Knight R. Medical practice areas in England: some facts and figures. Health Trends 1976;8:8-12

Bone M. Registration with general medical practitioners in inner London. London HMSO, 1984.

8 Dennis N, Havelock G. How easily can practices be contacted during normal working hours. I R Coll Gen Pract 1988;38(306):32-3.

9 Kronenfeld JJ. Organisation of ambulatory care by consumers. Sociology of Health and Illness 1982;4(2):183-200.

10 Hibbard JH, Weeks EC. Consumerism in health care-prevalence and predictors. Medical Care 1987;25(11):1019-32.

\title{
Doubtful gains from tighter consultant contracts
}

\author{
W J Appleyard
}

A deputy editor of the $B M \mathcal{F}$, Dr Tony Smith, interviewed Dr W J Appleyard on the working paper on consultant contracts and distinction awards. Dr Appleyard is a member and former deputy chairman of the Central Committee for Hospital Medical Services.
Kent and Canterbury Hospital, Canterbury, Kent CT1 3NG

W J Appleyard, FRCP, consultant paediatrician

BrMed f 1989;298:739-41
Let's talk first about the sensitive matter of contracts. Consultants are worried on two counts: who will really control their contracts and how flexible these will be in form and in daily operation.

We are told that as the trust hospitals evolve consultants' contracts are going to be held by these hospitals and not by the regional health authority. Traditionally, NHS contracts have been held at the regional level (except for the university and postgraduate teaching hospitals). So in some ways the trust hospital might follow the pattern of the university hospital:

The advantage of contracts being held at region in terms of consultant work is that most of the specialist services that consultants provide are confined to one district. True, general medical and surgical services may be based in a single district, but most subspecialties are provided on a multidistrict basis and have a regional structure.

Increasingly, the pattern of patient services is of primary care by general practitioners, referral to the secondary consultant care service-in the hospital and in the community for the maternity, paediatric, psychiatric, and geriatric services - and then a further layer of tertiary care for the subspecialties and for those topics that require more intensive research in teaching centres. It is important to plan those services both nationally and regionally. If we allow the growth of trust hospitals to be totally independent and based on market forces any planning will be extremely difficult to sustain. The new trust hospitals may not be interested in the difficult cases, and they may be more concerned in getting rid of their waiting lists as a political or as a financial objective.

There are, however, certain advantages in independence-for example, for raising money and developing some services faster. But the risk is that the trust hospital may decide to offer only limited services. In recent years we have seen some important and cost effective changes in the integration of secondary care services within the community and the hospital. One example is geriatric services; the consultant geriatrician must be appointed to the district - not just a hospital and run the community sector as well. Mental health is the same. And of course in paediatrics we have for far too long been inefficient, keeping two service armsthe child health service and hospital paediatricsthough we are now moving towards integration. It is not spelt out in the white paper whether trust hospitals may take on these services and if so how. And if they take some bits on and not others that would create a disorganised service. It is also difficult to see what incentive would be provided for a trust hospital to keep beds available for emergencies. Currently we are being asked in the south east region to keep our intensive care beds filled $100 \%$ of the time. Now that is absolutely impossible to do in any acute service.

\section{. . . A London trust hospital might say" we are going to pay you half the amount because you are bound to earn a lot in private practice."}

Until now the regional status of consultant contracts has meant two things: firstly, we have had good specialist services, and secondly, the specialists have been prepared to work outside the big teaching centres. One important feature of the health service has been its even spread throughout the country. If we come to have just a few trust hospitals which concentrate skills we might destroy that concept of overall service.

\section{Experienced staff}

Another point about the contracts being held at regional level-a system, incidentally that Alain Enthoven supported-is that regions have staff who are able to cope with such complexities as complaints by patients, and so on. Ideally, I believe that contracts should stay at regional level, but some aspects could be delegated to the district. Of course, to some extent that happens now, with the district deciding the content of the contract and seeking approval from the region. One more important safeguard is that it is desirable 